\title{
Investigating the Potential Use of lonic Liquids in Pre-Treatment Application for Water Desalination
}

\author{
Hadil Abu Khalifeh ${ }^{1}$, Inas AlNashef ${ }^{2}$, Asiya Nazir ${ }^{1}$, Noora Al Mansoori ${ }^{1}$, Ibrahim Yousef ${ }^{1}$ and Awatif Sharhahabiel ${ }^{1}$ \\ ${ }^{1}$ Abu Dhabi University, Chemical Engineering Department, UAE \\ ${ }^{2}$ Khalifa University, Department of Chemical and Environmental Engineering, UAE
}

\begin{abstract}
The world has been noticing a quickening advancement over the last decades in terms of irrigated agriculture, social, industrial, and economical perspectives; followed by a huge increment in the water demand. Therefore, desalination is used all over the world to reduce worldwide water shortage; however, the traditional techniques lead to fossil fuel depletion and global warming. Therefore, scientists are investigating new green and environment-friendly methods to be used by the desalination plants to reduce $\mathrm{CO}_{2}$ emissions and save the natural resources. In this study, the feasibility of using ionic liquids (ILs) as potential means for pre-treatment of seawater desalination was examined. The main aim of this work was to examine the ability of ILs in extracting salts from saline water. As a first step, the solubility of $\mathrm{NaCl}, \mathrm{MgCl}_{2}$, and $\mathrm{CaCl}_{2}$ in different ILs at different temperatures were analyzed. The solubility of the salts in ILs increased in most cases with temperature increments; however, the presence of emulsion was seen in a few cases. The highest measured concentration of $\mathrm{NaCl}$ was $6,639 \mathrm{ppm}$ at $60{ }^{\circ} \mathrm{C}$ in 1,3-Dimethylimidazolium dimethyl phosphate.
\end{abstract}

\section{Introduction}

Water occupies $79 \%$ of the earth's volume; nonetheless, only $2.5 \%$ of the total water is fresh water. The population is growing dramatically over the years and so is the demand on fresh water. Moreover, the expansion of irrigated agriculture and industrial advancement play a major role besides the population growth in increasing fresh water demand. Hence, saline water needs to be desalinated in order to provide more fresh water for the next generations. The typical method used in the distillation plants is the sea water reverse osmosis; however, to produce $1 \mathrm{~m}^{3}$ of fresh water, $3-10 \mathrm{~kW}$ of electric energy is required [1]. The typical desalination plants depend on fossil fuels to afford this amount of energy which leads to increased fossil fuel depletion and $\mathrm{CO}_{2}$ emission. Nowadays, finding a clean method for desalinating water is a top priority.

In this study, ILs will be evaluated to be used as means in the pre-treatment process in desalination plants. Even though ILs were initially defined in 1914, a noticeable consideration has been focused on utilizing ILs as a replacement to the traditional hazardous solvents in recent years $[2,3]$. This was due to their unique and safe characteristics, such as, the feasibility of reusing, low vapor pressure, and low flammability [4]. This study is composed of two stages: Firstly, the solubility of single three different salts $\left(\mathrm{NaCl}, \mathrm{MgCl}_{2}\right.$, and $\left.\mathrm{CaCl}_{2}\right)$ in different ILs is tested at five different temperatures $(25,45,60,80$ and $100^{\circ} \mathrm{C}$ ). Secondly, the solubility of combined three different salts $\left(\mathrm{NaCl}, \mathrm{MgCl}_{2}\right.$, and $\left.\mathrm{CaCl}_{2}\right)$ in different ILs is measured at five different temperatures $(25,45,60,80$ and $100^{\circ} \mathrm{C}$ ). The results obtained in this stage are taken as a reference for extracting salts from saline water.

A recent study suggested that the presence of inorganic salts in ILs increases the ionicity of the ILs as salts empower the charge density of the IL [5]. A previous work was conducted for evaluating the solubility of $\mathrm{NaCl}$ in different ILs at different temperatures, and it was concluded that the solubility of $\mathrm{NaCl}$ and temperature have a proportional relationship and that $\mathrm{NaCl}$ is more soluble in imidazolium-based ILs than pyrrolidinium- and ammonium based ILs [6]. A recent study investigated the solubility of $\mathrm{NaCl}$ in different phosphonium-based DESs as a function of temperature and the salt: HBD (hydrogen bond donor) or metal halide molar ratio. The results show that increasing the temperature and the amount of HBDs or metal halides in the DES increases the solubility of $\mathrm{NaCl}$ in the DESs. The chemical structure of the DES significantly affects the solubility of $\mathrm{NaCl}$ in the studied DESs. The study tested the ability of different Trioctyl ammonium based ILs in extracting $\mathrm{NaCl}$ from water, extraction was higher in a small anion based ILs because NaCI could easily diffuses between the cation and anions of the IL. Meanwhile with large anion based ILs the diffusion of $\mathrm{NaCI}$ is less; hence, lower extraction efficiency [7]. The benefit of using hydrophobic ILs in extraction is due to the elimination of water and IL cross-contamination. The hydrophobic ILs consist of the imide anion which 
contributes to their hydrophobic nature. The parameters to study are: temperature, type of salt, water to IL mass ratio, and IL structure. The results in this stage determine the feasibility of using ILs as part of the pre-treatment processes in desalination plants.

If the hypothesis is approved, then more fresh water will be produced from environmental friendly methods. This will subsequently diminish the salinity of seawater and decrease the stack on desalination plants; hence, the vital necessities will be reduced. Furthermore, this will significantly lessen the fouling and scaling of membranes generated by the salts' deposition, leading to decreased expenses as less maintenance services will be required and resources will be saved.

\section{Methodology}

\subsection{Materials}

Three different salts were used in this study namely, sodium chloride, magnesium chloride, and calcium chloride. The salts were supplied by Sigma-Aldrich. The specified salts were selected because of their significant concentration in seawater. Furthermore, ILs used in this study were purchased from Ionic Liquid Technologies, IoLiTec, (Heilbronn, Germany). Each ionic liquid from the selected ILs had different cation and/or anion. Also, some ILs were hydrophilic and the others were hydrophobic. The hydrophilic IL was only used in the solubility study alongside with one hydrophobic IL. Table 1 shows two of the ILs used in the solubility measurements part.

Table 1. Ionic Liquids used for salt solubility experiments.

\begin{tabular}{|c|c|}
\hline $\begin{array}{c}\text { IL } \\
\text { Number }\end{array}$ & IL Name \\
\hline 14 & 1,3-Dimethylimidazolium dimethyl phosphate \\
\hline 15 & $\begin{array}{c}\text { Methyltrioctylammoniumbis } \\
\text { (trifluoromethylsulfonyl) imide }\end{array}$ \\
\hline
\end{tabular}

\subsection{Equipment}

An analytical balance was used to measure the required mass of the salts. Eppendorf Thermomixer ${ }^{\circledR} \mathrm{C}$ (Germany) was used to heat and mix the samples to the desired temperature. The concentration of the salts in ILs was determined by ICP-OES (Inductively Coupled PlasmaOptical Emission Spectrometry). Lastly, the water content of the ILs was measured using Aquamax Coulometric Karl Fischer Titrator.

\subsection{Solubility procedures}

The solubility procedure was conducted for several mixtures of salts and ILs. Table 2 summarizes the salt/IL combinations used for salt solubility test.
Table 2. All salt/IL combinations used for the solubility measurements.

\begin{tabular}{|c|c|c|}
\hline Sample & IL & Salt \\
\hline 1 & IL 14 & $\mathrm{CaCl}_{2}$ \\
\hline 2 & IL 14 & $\mathrm{MgCl}_{2}$ \\
\hline 3 & IL 14 & $\mathrm{NaCl}$ \\
\hline 4 & IL 15 & $\mathrm{CaCl}_{2}$ \\
\hline 5 & IL 15 & $\mathrm{MgCl}_{2}$ \\
\hline 6 & IL 15 & $\mathrm{NaCl}$ \\
\hline
\end{tabular}

The samples presented in Table 2 consisted of roughly $3 \mathrm{~g}$ of IL and $0.2 \mathrm{~g}$ of salt. Each of the samples tabulated in Table 2 was mixed at a set of different temperatures $\left(25,45,60,80\right.$ and $\left.100{ }^{\circ} \mathrm{C}\right)$ using the Eppendorf Thermomixer ${ }^{\circledR} \mathrm{C}(5 \mathrm{~mL})$ at a speed of 600 rpm for 16 to 24 hours and then allowed to settle down. At each temperature, a sample of $0.1 \mathrm{~g}$ of the IL mixture was taken and placed in a $50 \mathrm{~mL}$ polypropylene centrifuge tube. Each sample was diluted with $50 \mathrm{~mL}$ of deionized water in order to accommodate the ICP equipment specification. The diluted samples were analyzed using ICP.

\section{Results and discussion}

The experimental results are based upon two main experimental procedures; first, solubility of salts in Hydrophilic ILs at different temperatures, and second, the solubility of salts in Hydrophobic ILs at different temperatures. Salts solubility was tested individually in each IL. The solubility of salts in the tested ILs at different temperatures is shown in Tables 3, 4 and 5. Also, Karl Fischer Titration was used to determine the water content of pure ionic liquids. The water content data obtained from the Karl Fischer Titration is reported in Table 5. The water content of ILs is very important since it can affect the physiochemical properties of ILs. As mentioned earlier, the first step for the research analysis is to measure the solubility of the three salts in ILs and keep the results as a reference. The solubility was measured for each salt separately in each of the listed ILs in Table 1 at different temperatures.

Firstly, the solubility of $\mathrm{MgCl}_{2}$ was measured in the ILs at different temperatures. The results are listed in Table 3 and shown in Figures 1 and 2.

Table 3. Solubility results for $\mathrm{MgCl}_{2}$ at different temperatures.

\begin{tabular}{|c|c|c|c|c|c|}
\hline \multicolumn{5}{|c|}{$\mathrm{MgCl}_{2}$} \\
\hline \multirow{3}{*}{ IL } & \multicolumn{5}{|c|}{ Temperature $\left({ }^{\circ} \mathrm{C}\right)$} \\
\cline { 2 - 6 } & 25 & 45 & 60 & 80 & 100 \\
\cline { 2 - 6 } & \multicolumn{5}{|c|}{ Concentration (ppm) } \\
\hline 15 & 220.55 & 90.95 & 51.85 & 169.05 & 149.63 \\
\hline 14 & 3,809 & 8,275 & 8,478 & 9,540 & 15,115 \\
\hline
\end{tabular}




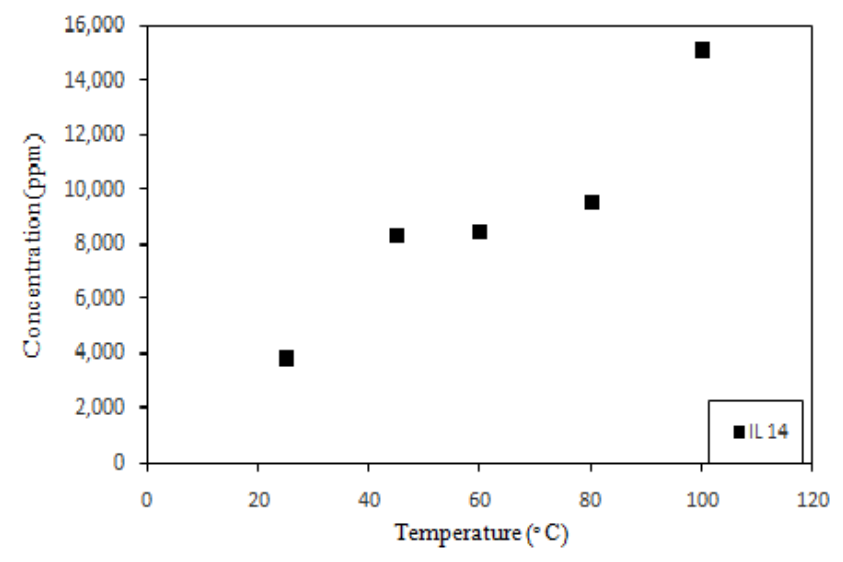

Figure 1. $\mathrm{MgCl}_{2}$ solubility in IL14 at different temperatures.

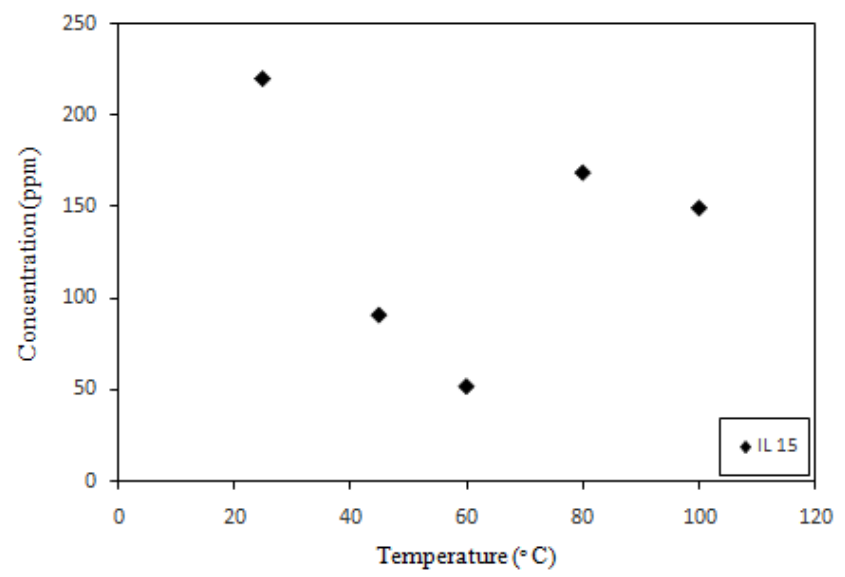

Figure 2. $\mathrm{MgCl}_{2}$ solubility in IL15 at different temperatures.

IL14 has shown the best solubility results of $\mathrm{MgCl}_{2}$ at all temperatures with the maximum concentration of $15,115 \mathrm{ppm}$ at $100^{\circ} \mathrm{C}$. The results have shown a trend of increasing solubility with increasing temperature, but this was not followed by IL15. The solubility of $\mathrm{MgCl}_{2}$ decreased from $25^{\circ} \mathrm{C}$ to $60^{\circ} \mathrm{C}$ and then increased.

Then, the solubility of $\mathrm{NaCl}$ was examined at different temperatures and listed the results in Table 4 and plotted in Figure 3 and Figure 4. Again, IL14 showed the best solubility amongst other ILs with the highest solubility of $6,639 \mathrm{ppm}$ at $60^{\circ} \mathrm{C}$ and remained approximately constant with increasing temperature. Additionally, the hydrophobic IL15 showed the lowest results that remained constant throughout the temperatures. Clearly, the solubility of $\mathrm{MgCl}_{2}$ in the tested ILs is much higher than $\mathrm{NaCl}$.

Table 4. Solubility results for $\mathrm{NaCl}$ at different temperatures.

\begin{tabular}{|c|c|c|c|c|c|}
\hline \multicolumn{5}{|c|}{$\mathrm{NaCl}$} \\
\hline \multirow{3}{*}{ IL } & \multicolumn{5}{|c|}{ Cemperature $\left({ }^{\circ} \mathrm{C}\right)$} \\
\cline { 2 - 6 } & 25 & 45 & 60 & 80 & 100 \\
\cline { 2 - 6 } & \multicolumn{5}{|c|}{ Concentration (ppm) } \\
\hline 15 & 85.25 & 84.34 & 85.07 & 82.67 & 84.03 \\
\hline 14 & 1,045 & 5,845 & 6,639 & 6,504 & 6,540 \\
\hline
\end{tabular}

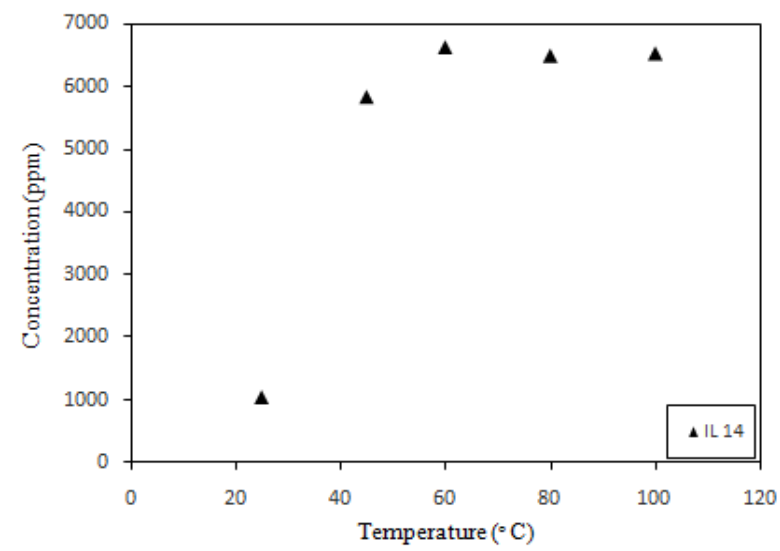

Figure 3. $\mathrm{NaCl}$ solubility in IL14 at different temperatures.

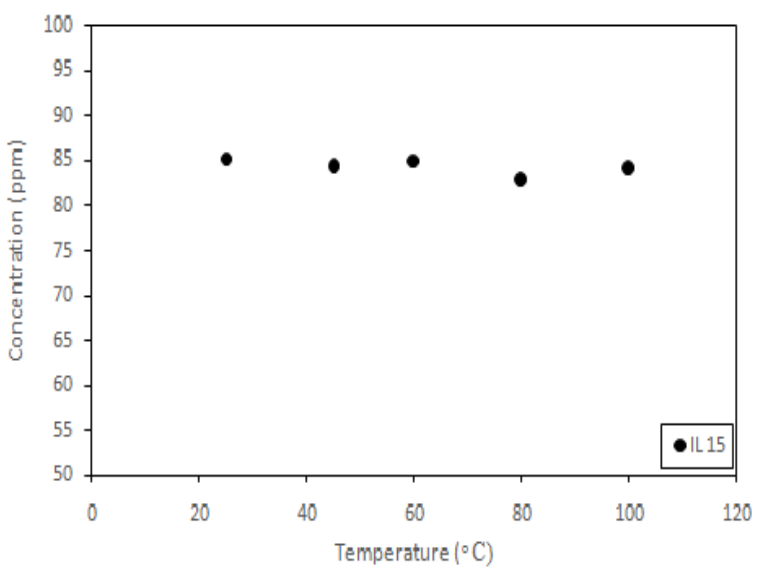

Figure 4. $\mathrm{NaCl}$ solubility in IL15 at different temperatures.

As per of $\mathrm{CaCl}_{2}$, the solubility results are presented in Table 5. The highest solubility was $1,393 \mathrm{ppm}$ at $25^{\circ} \mathrm{C}$ in IL14. It was suspected that a chemical reaction took place in which the ions were exchanged between the salt and IL; cation (Calcium) from the salt transferred to the ionic liquid and combined with the IL anion (dimethyl phosphate) and the cation from the ionic liquid transferred to the salt. Further analysis was performed using FTIR which confirmed that a chemical reaction did indeed take place. We couldn't further observe the solubility change with temperature as it solidified at $45^{\circ} \mathrm{C}$. As shown in Figure 5, for IL15, an emulsion formed through $45^{\circ} \mathrm{C}$ to $80^{\circ} \mathrm{C}$ which prevented measuring the solubility, but the concentration decreased between $25^{\circ} \mathrm{C}$ and $100^{\circ} \mathrm{C}$ which contradicts with the trend showed by the previous salts.

Table 5. Solubility results for $\mathrm{CaCl}_{2}$ at different temperatures.

\begin{tabular}{|c|c|c|c|c|c|}
\hline \multicolumn{5}{|c|}{$\mathrm{CaCl}_{2}$} \\
\hline \multirow{3}{*}{ IL } & \multicolumn{5}{|c|}{ Temperature $\left({ }^{\circ} \mathrm{C}\right)$} \\
\cline { 2 - 6 } & 25 & 45 & 60 & 80 & 100 \\
\cline { 2 - 6 } & \multicolumn{5}{|c|}{ Concentration (ppm) } \\
\hline 15 & 570.10 & Emulsion & Emulsion & Emulsion & 224.60 \\
\hline 14 & 1,393 & Emulsion & - & - & - \\
\hline
\end{tabular}




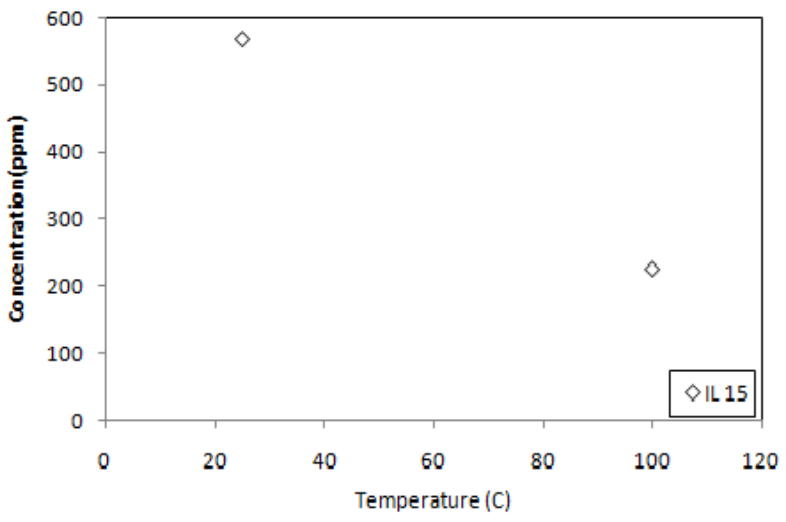

Figure 5. $\mathrm{CaCl}_{2}$ solubility in IL15 at different temperatures.

An experiment was conducted using the Karl Fischer Titrator to measure the water content in pure IL. Table 6 shows the results for the percentages of water content in pure IL. Water content helps to determine whether ILs can be recycled and reused for further saline water extraction processes as we consider the efficient ionic liquid that has the least water uptake; thereby, we reduce the amount of resources needed and the cost of the overall process.

Table 6. Water content of ILs using Karl Fischer Titrator.

\begin{tabular}{|c|c|}
\hline IL & \% of Water content in Pure I.L. \\
\hline 15 & $0.0928 \%$ \\
\hline
\end{tabular}

${ }^{b}$ The K-F titration test was done on the pure hydrophobic ILs.

\section{Conclusion}

In this work, the potential of using ionic liquids as a part of the pre-treatment process for seawater desalination was investigated. The analysis was initiated by measuring the solubility of sodium chloride, magnesium chloride, and calcium chloride in the selected ionic liquids at different temperatures. The solubility of all three salts increased with increasing temperature. IL14 has shown the best solubility results with $\mathrm{MgCl}_{2}$ salt with the maximum concentration of $15,115 \mathrm{ppm}$ at $100^{\circ} \mathrm{C}$, and $\mathrm{NaCl}$ with $6,639 \mathrm{ppm}$ concentration at $60^{\circ} \mathrm{C}$, and $\mathrm{CaCl} 2$ with $1,393 \mathrm{ppm}$ at $25^{\circ} \mathrm{C}$. The results showed that the solubility of $\mathrm{MgCl}_{2}$ in the tested ILs is much higher than that of $\mathrm{NaCl}$ and $\mathrm{CaCl}_{2}$. It was found that $\mathrm{IL} / \mathrm{CaCl}_{2}$ mixture solidified at temperatures higher than $25^{\circ} \mathrm{C}$.

In conclusion, the overall results of the research work show a great potential of using ILs in the pre-treatment process as it reduces the fouling effect on the membranes by primarily extracting the inorganic salts. Also, considering using an efficient ionic liquid with lowest water uptake that can be recycled and reused again for repeated extraction processes.

\section{References}

1. R. Dashtpour and S. Al-Zubaidy, Intern. J. of Envi. Sci. and Develop., 3 (2012)

2. Walden, P. Bull Acad. Imper. Sci., 1291. (1929)

3. C. L Hussey Adv. Molten Salt Chem., 5, 185. (1983)

4. T. Welten, Chem. Rev., 2071. (1999).

5. A. Pereiro, J. Araújo, F. Oliveira, J. Esperança, J. Canongia Lopes, I. Marrucho et al. , J. of Chem. Thermo., 55, pp:29-36. (2012)

6. F. GharehBagh, F. Mjalli, M. Hashim, M. Hadj-Kali and I. AlNashef, Ind. \& Eng. Chem. Res., 52, pp.11488-11493. (2013).

7. C. Janssen, M. Kroon, S. Metz, J. van Spronsen and G. Witkamp, J. of Chem. \& Eng. Data, 55(9), pp. 3391-3394. (2010). 